\title{
Visual elements in children's concrete poems: A multimodal analysis of Rain and Ice Cubes
}

\author{
Thusha Devi Rajendra \\ thushad4@yahoo.com \\ University Malaya \\ Surinderpal Kaur \\ surinder@um.edu.my \\ University Malaya
}

\begin{abstract}
This study is based on the multimodal analysis of two children's concrete poems from the poetry book, Splish Splash (1994) by Joan Bransfield Graham. It employs Kress and van Leeuwen's (2006) Visual Grammar as the analytical tool to analyse the visuals in terms of compositional meaning. It investigates how visual elements (words and images) are represented in the poems. In addition, it focuses on the features of the images and how they cohere on a page. The findings suggest that the representations of images in the poems reproduce the dominant theme of water and its forms. Furthermore, the interrelatedsystems of salience and framing are used extensively and they contribute to meaningmaking. Words and images support each other and coexist to provide meanings in the poems. Therefore, the combination of words and images creates a meaningful whole and offers readers greater opportunities to create meanings.
\end{abstract}

Keywords: Concrete poetry, multimodal analysis, compositional meaning, salience, framing 


\section{Introduction}

Concrete poetry is often referred to as shape, visual or pattern poetry in which the arrangement of words on the page forms the shape of its subject. Although concrete poetry is a popular form of children's poetry, children are often taught to pay attention to its shape as it is the most distinct and recognizable quality. Nonetheless, all other elements that coexist with or within concrete poems are equally and significantly important to communicate meanings.

This article explores how visual elements (words and images) are represented in children's concrete poems. It particularly focuses on the different features of these elements and how they coalesce and work together on a page. This study utilizes Kress and van Leeuwen's (2006) Visual Grammar (VG hereafter) as the analytical tool to analyse the visuals in terms of compositional meaning. It investigates how visual elements are inextricably linked to create unity, coherence and meaning in a multimodal ensemble. Most importantly, the analysis pursues Serafini's (2014) view that in today's contemporary environment, literacy instructional practices should not solely focus on decoding written language given the multimodal nature of modern communication which encompasses visual images. Therefore, concrete poems are employed in the study as the amalgamation of different visual elements provide a multi-literacy experience in the classroom.

\section{Concrete Poetry}

Concrete poetry brings a visual orientation to the structure of the poem as words are organised in non-linear patterns across the page. Thus, the overall organization of the lines in the poem creates a visual image of the content.

The concrete poetry's full meaning potential can only be evoked and understood when it is seen in its spatial arrangement within the layout. Accordingly, Bodden (2010) postulates that while most traditional poems are meant to be read, concrete poems are meant to be seen. Bohn (2011) posits that the visual dimension is an integral part of concrete poetry as it develops and expands the verbal text. He further reiterates that although concrete poetry takes on many forms, it inevitably combines pictures with words. However, little is known as how the different semiotic resources integrate and cohere to construct meanings in concrete poems.

Academic works on concrete poetry mainly centred on the many features of concrete poetry. A study conducted by Joshi (2009) on an international corpus of visual concrete poetry, investigated translatability and untranslatability in terms of script, language and iconicity. Shen 
and Wu (2012) carried out a study on English translation of Taiwanese concrete poems and reported that there was an unavoidable loss of Chinese distinctive images when presenting the concrete poems in English. On the other hand, Knowles, Schaffner, Weger and Roberts' (2012) study on visual poems denoted that space played a significant role in irregular visual poems. This is because their reading paths elicited more diverse and subjective responses as compared to linear visual poems.

Furthermore, Wang (2012) employed Halliday's Systemic Functional Grammar (SFG hereafter) and Kress and Van Leeuwen's VG to analyse the visual poem in Just- by E.E. Cummings. However, she discussed both the visual and textual modes in isolation. Therefore, the integration and contribution of these modes in meaning-making was not clearly stated or analysed. Interestingly, Meyer (2017) utilized auto-ethnographic methods to carry out a metaphor analysis. She used concrete poetry to illustrate the visual representation of data generated from a study on the challenging aspects of being a single mother of a child with mental illness. The findings revealed that the emotional states suggested by the respondents' metaphors were in accordant with the literature on parenting children with disabilities.

As illustrated above, the studies focused on the different aspects of concrete poetry and thus, the scarcity on the analysis of children's concrete poems is evident. Therefore, this study addresses the gap and adds to the contribution to studies on concrete poetry, with specific reference to children's concrete poems. Children's concrete poems are often accompanied by visual images. This study focuses on the visual elements of children's concrete poetry and how they combine to communicate meanings. Thus, it answers the research question "How are visual elements represented in children's concrete poems?"

\section{Multimodal Analysis}

Multimodality is a term propounded by the New London Group in 1996 and it refers to all modes that are available and used in constructing meaning in representation and communication (Kress, 2008). Hence, multimodal analysis looks at the integration of semiotic resources, the affordance of each resource and how each semiotic resource combines with other semiotic resources and communicate meaning in a multimodal ensemble (Jewitt, 2009). In relation to this, Serafini (2014) defines multimodal ensemble as a complex multimodal entity that deploys a variety of cultural and semiotic resources to articulate, represent and communicate an array of concepts and information. 
Concrete poetry could be considered as a multimodal ensemble as it is a combination of semiotic resources such as words, images, typography, colours, shapes and space that are coherently organised on the page.

Borkent (2010) opines that concrete poetry utilizes textual and visual resources to communicate meaning. Therefore, the textual resources in concrete poems consist of words, typography, space and other semiotic resources. According to Baldry and Thibault (2006), writing is weaved with the principles of visual design as the graphological elements (punctuation, capitalization, lower cases of letters, hyphen and so on) of the written language utilize the possibilities provided by other visual semiotic resources. The graphological elements which are important in the creation of meanings in poetry are also synonymous to concrete poetry as they are pivotal to construe meanings in the poems.

There has been a number of studies conducted in the field of multimodality in recent years. These studies have proven that VG is popular and generally preferred as a tool to analyse images and pictorial texts especially in socio-semiotic approach and MDA. Nevertheless, VG is often used concurrently with other frameworks especially Halliday's SFG for analysing multimodal texts. Eleftheriou, Stamou, Alevriadou and Tsakiridou (2013) put forth that different models or frameworks have been developed for the analysis of visual and verbal elements because of their distinctive and inherent features.

The prevalence of multimodal ensembles in recent years had contributed to many studies conducted on the domain of multimodality. Moya and Pinar (2008) carried out a multimodal analysis using Kress and van Leeuwen's VG and Halliday's SFG to determine the extent visual and verbal components cohere to produce and convey compositional, interpersonal and representational meanings. Moya (2010) utilized the same frameworks (VG and SFG) to analyse the interpersonal meanings communicated by the verbal and visual components in The Tale of Peter Rabbit. The findings indicated that the combination of language and visuals strengthen and reinforce the reader's identification with the main character in the story.

In addition, Eleftheriou et al (2013) employed Kress and van Leeuwen's VG on a comparative study to examine the representations of disability on drawings that were produced by primary school students in Greek. The findings suggested that children tend to produce drawings based on the ideas that they have about disability and people with disabilities. 
Furthermore, Salbego, Heberle and Balen's (2015) study discussed how multimodal analysis of English textbooks supports learning by utilizing Kress and van Leeuwen's VG. Rajendra's (2016) study employed Halliday's SFG, Kress and van Leeuwen's VG, McCloud's (1994) Panel-to-Panel Transitions (PPT) and Nikolajeva and Scott's (2006) Text Image Interaction (TII) to examine how comics are represented in adapted graphic novels used in Malaysian secondary classrooms. The results highlighted that the writers and illustrators of the novels conformed to certain linguistic and image structures to support and reinforce the close adaptions of the original works.

Other multimodal studies which concentrated on different multimodal domains are children's Bible illustrations (John \& Olajoke, 2012), German newspapers (Jumaah, 2019), covers of chick-lit books (Khoo,2019), photographs and packaging (Ledin \& Machin, 2018), children's picture books (Robertson, 2008) and tourism brochures (Tan, 2017)

Though all these studies focus on multimodal analysis, multimodal studies on concrete poems are scarce as discussed earlier. On this basis, this study employs Kress and van Leeuwen's VG to explore how visual elements are represented in children's concrete poems.

\section{Theoretical Framework}

\subsection{Kress and van Leeuwen's Visual Grammar (VG) Framework}

Kress and van Leeuwen's VG (2006) which expands on Halliday's Systemic Functional Grammar (SFG) (1994) is employed to realize the visual meanings in children's concrete poems. This descriptive framework that assigns representational, interactional and compositional meanings to images is used as a tool to analyse the inherent features and elements in children's concrete poems and how they combine to construct meanings.

However, only compositional meaning is considered for this study as the focus is on how different visual elements are structured to convey meanings on the page. In addition, the study is concerned with the organisation of visual elements in children's concrete poems and establishing coherence and ordering among them. The visual elements encompass the concrete poems and the accompanying images in the layout. Kress and van Leeuwen (2006) define composition as a means by which different semiotic resources are integrated into a meaningful whole. Furthermore, Painter, Martin, and Unsworth (2013) posit that verbal text could be considered as a graphic phenomenon and exists as a visual element, either overlaid onto the image itself or separated out 
into its own identifiable space in the layout. Hence, concrete poems which appear within an image or space is considered as a visual element. In sum, Kress and van Leeuwen's VG (2006) appears to be a useful analytical tool to analyse the data (concrete poems) which combines words, images, typography, colour and other visual elements.

\subsubsection{Compositional Meaning}

'Compositional' meaning parallels Halliday's (1978) third meta-function of SFG which is textual meta-function. According to Kress and van Leeuwen (2006), compositional meaning puts together the representational and interactional meta-functions to create a meaningful and significant whole.

Compositional meaning comprises the interrelated systems of information value, framing and salience. These interrelated systems (Eleftheriou et al, 2013) are relevant to individual visual images or a combination of various semiotic resources as in children's concrete poems.

However, this paper focuses on the interrelated systems of salience and framing as they are applicable to children's concrete poems. The interrelated system of informational value that refers to the positioning of semiotic objects in the various zones (spatial dimensions) is not employed as it is more appropriate for advertisements and magazine layouts. In addition, information value is open to different or multiple interpretations where the validity of the statements is difficult to assess (Bateman, 2008).

Salience denotes that some elements in compositions can be made more eye-catching or appealing to draw the viewers' attention. On the other hand, framing signifies the presence or absence of framing devices where they either connect or disconnect the elements within a layout. Therefore, these framing devices either provide separate identities to the elements or represent the elements as being together within a spatial layout.

The features of salience and categories of framing are illustrated in Table 1 and Table 2 respectively. 
Table 1: Features of Salience

\begin{tabular}{ll}
\hline Features & \multicolumn{1}{c}{ Description } \\
\hline Placement & The location of an element \\
Size & The biggest element in a composition \\
Colour & Bold rich colours \\
Tone & The brightness of an element \\
Focus & An element in focus \\
Foregrounding & A foregrounded element \\
Overlap & An element that is superimposed on another \\
& element \\
\hline
\end{tabular}

(Adapted from Kress and van Leeuwen, 2006)

Table 2: Categories of Framing

\begin{tabular}{|c|c|}
\hline Categories & Description \\
\hline Segregation & $\begin{array}{l}\text { - } \quad \text { Elements are separated by lines or frames } \\
\text { - } \quad \text { Establishes a boundary }\end{array}$ \\
\hline Separation & $\begin{array}{l}\text { - Elements are separated by empty space } \\
\text { - No physical border }\end{array}$ \\
\hline Integration & $\begin{array}{l}\text { - Elements occupy the same space } \\
\text { - Leads to a natural connectivity }\end{array}$ \\
\hline Rhyme & $\begin{array}{l}\text { - Elements that are linked through colour, size, shape and } \\
\text { so forth }\end{array}$ \\
\hline Contrast & $\begin{array}{l}\text { - Elements that disconnect through colour, size, shape } \\
\text { and so forth }\end{array}$ \\
\hline Repetition & $\begin{array}{l}\text { - Elements that are repeated like colours and shapes } \\
\text { - Creates unity and cohesion }\end{array}$ \\
\hline Overlap & $\begin{array}{l}\text { - Elements that extend onto spaces of other elements and } \\
\text { not constrained by frames }\end{array}$ \\
\hline
\end{tabular}

(Adapted from van Leeuwen, 2005)

\section{Research Methodology}

Based on Kress and van Leeuwen's VG (2006), the study focuses on how visual elements are represented in Rain and Ice Cubes. Both these concrete poems are taken from Splish Splash, a 
specialized water themed collection of children's concrete poems. These $20^{\text {th }}$ century modern concrete poems are written by Joan Bransfield Graham, an award-winning children's poet with illustrations by Steve Scott. Although 21 concrete poems are featured in this collection, only Rain and Ice Cubes are discussed in this paper due to page limitation. Rain and Ice Cubes are chosen specifically as they take into account almost all the different features of salience and categories of framing.

The first step of the analysis is to identify the salient elements and the ways they are made salient in Rain and Ice Cubes. This is determined through the features of salience such as size, placement, colour, foregrounding and so forth. The next step involves investigating how framing is deployed to connect and disconnect the various elements in the layout. The analysis then proceeds with the discussion of how visual elements are represented in Rain and Ice Cubes. Subsequently, the findings are discussed in terms of how the individual signs are able to co-exist coherently with the context in which they are produced (Machin, 2007).

\section{Visual Analysis of Rain and Ice Cubes}

The following discussion focuses on how visual elements are represented in Rain and Ice Cubes in terms of salience and framing. Apart from existing as verbal elements (words), both Rain and Ice Cubes stand out as visual elements as they form raindrops and ice cubes respectively. This is illustrated in Figure 1 where the concrete poem Rain is a stand-alone and also part of a composition. The concrete poem is integrated with other images such as daisies and raindrops to form a unified whole. Hence, the concrete poem and the images coalesce to reinforce and complement each other. This proves Nikolajeva and Scott's (2006) theory that an effective balance exists when pictures complement words to strengthen the ultimate effect.

In the discussion, shapes, circles and arrows are used to draw attention to an important element of the image that is being analysed. 


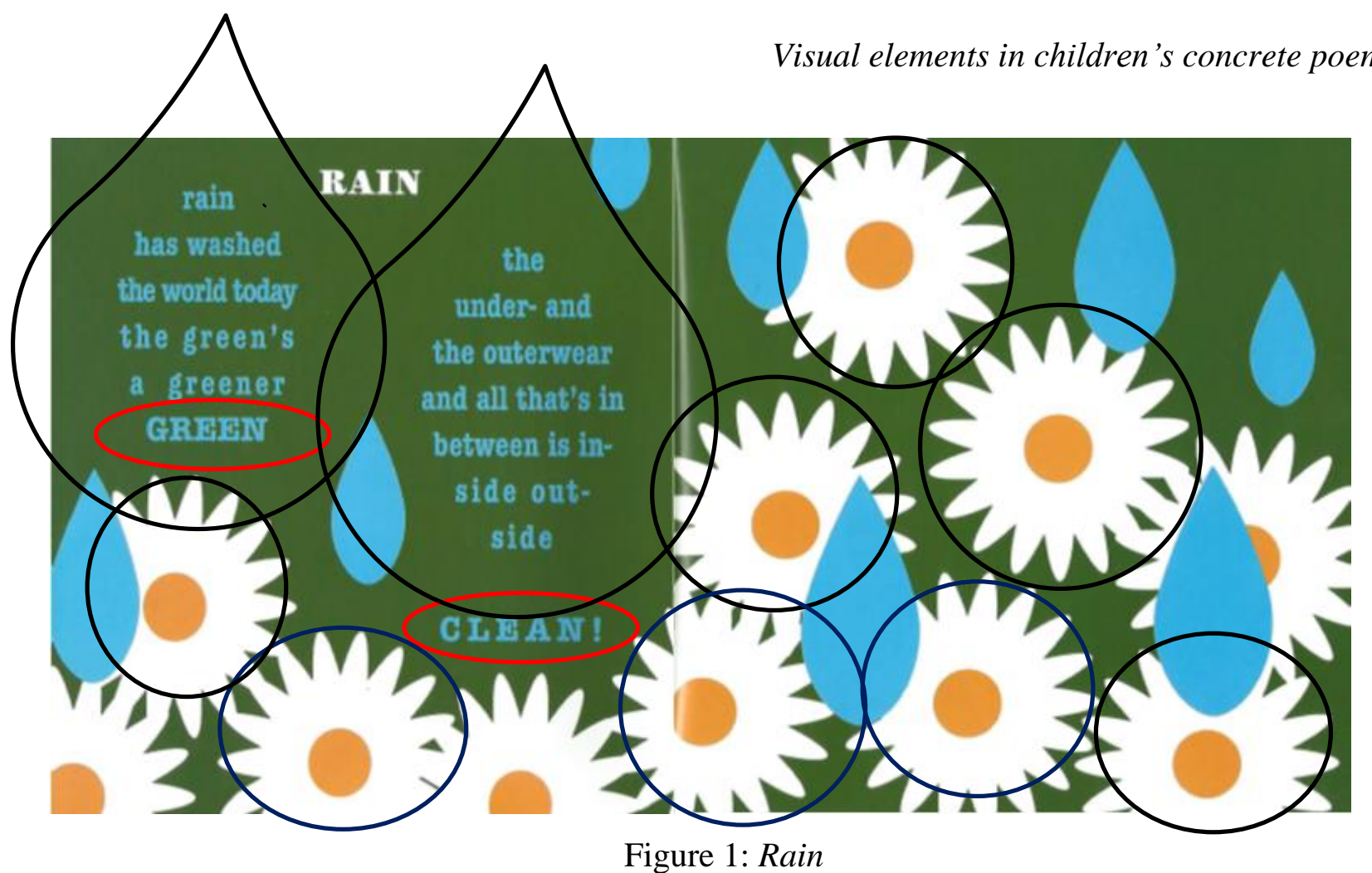

From SPLISH SPLASH. Text Copyright [c]1994 by Joan Bransfield Graham. Illustrations Copyright [c] 1994 by Steve Scott. Reprinted by permission of Houghton Mifflin Harcourt Publishing Company. All rights reserved.

The first poem, Rain makes full use of a double-page spread where salience is achieved through size, colour, placement, foregrounding and overlap. The repetition, placement and overlapping of daisies (denoted by black circles) make them the most salient elements on the double- page spread. In addition, the daisies are the largest elements and they appear throughout the double-page spread, thus making them the dominant images.

The daisies that are made up of white petals and orange centres are visually arresting against the dark green backdrop. The dark green backdrop denotes the leaves of the daisy plant that are clumped together. Therefore, the leaves are not visible. According to van Leeuwen (2011), colour provides salience that helps draw attention to elements of importance. Hence, colour, size and placement of the daisies make them prominent in the layout.

The adjectives GREEN and CLEAN which are depicted by the red oblong shapes appear in isolation and provides weightage to further emphasize the effects of rain on the environment. The increase in weight and size contributes to salience and emphasizes the adjectives GREEN and CLEAN. This concurs with Serafini's (2014) claim that one should not only consider what is written but how it is presented as it is fundamental in the interpretation of multimodal ensembles. He further stresses that different typographical rendering of the same text can totally indicate different meanings. In addition, the adjectives GREEN and CLEAN expand the meaning of the 
images in the poem. The adjective GREEN aptly describes the green leaves that had become vividly bright after the rain because of the reflection from sunlight. Likewise, Akcay, Dalgin, and Bhatnagar (2011) view that the colour white connotes purity and cleanliness (cited in Cheong and Kaur, 2015). This is represented by the adjective CLEAN which suggests the appearance of the daisies and the leaves after the rain.

The repetition and placement of the daisies are foregrounded on the lower left-hand page and they take up almost all of the space on the right-hand page. According to Serafini (2011), the placement of objects determines their importance and how they interact with other objects in a visual composition. The blue raindrops that overlap the daisies and the backdrop, draw the reader's attention as the contrasting colour (blue) stands out against the white daisies. Nevertheless, the raindrops that vary in size seem to be subdued against the fonts of the concrete poem. This is because the fonts share the same blue as the raindrops and they do not appear attractive against the dark green background. The organic shapes of the daisies and raindrops also provide different meanings and create a consistent look across the printed page (Md Sidin Ahmad Ishak, 2007). Here, the organic shapes represent things that appear in nature and adds to the visual interest in Rain.

In terms of framing, Rain has a combination of five framing categories; integration, contrast, rhyme, repetition and overlapping. The raindrop shaped concrete poem is placed against the green backdrop. Subsequently, the poem operates multimodally as a verbal and visual image. It integrates with the backdrop and this guides the reader to view it as one unit of information.

Although the contrasting colours of the fonts for both the title and the lines of the poem lend themselves to disconnection, they provide emphasis in the layout as they differentiate the title and the poem. Furthermore, the contrasting colours of the fonts do not generate detachment between the elements as they are linked together by the framing device of rhyme. Rhyme coordinates specific colours with other elements on the page. In relation to this, the white of the title 'RAIN' rhymes with the petals of the daisies. On the other hand, the blue employed for the lines in the poem depicts the colour of raindrops. It also rhymes with the colour of the raindrops in the layout. Thus, the white and blue fonts create links across the compositional elements (Kabuto, 2009). This bolsters Kress and van Leeuwen's (2002) assertion that textual cohesion can be promoted by colour coordination rather than repetition of a single colour. 
The contrasting size and shapes of the daisies and raindrops are deliberately arranged to be in conflict with one another. However, contrast also suggests a variety in the design as the contrast in size and shape, type (typography), and colour works and fits together in the layout.

Furthermore, the link is evident through the repetition of colour and shape as depicted by the daisies and raindrops. This not only promotes unity but ties these elements together, thus making them work harmoniously.

Moreover, the overlapping of the daisies and raindrops serves to connect both the pages as they seamlessly move from one page to another to create a unified whole. It can be deduced that the illustrator utilized the technique of overlapping to connect the different elements as a single unit of information. Overlapping also represents togetherness as interference through mutual modification of shape. According to Arnheim (1974), overlapping is more enthralling when it occurs within a visual unit as illustrated in Rain.

Therefore, the different features of salience combined with the categories of framing in Rain establish cohesion throughout the layout. For example, the foregrounding, overlapping and repetition of the daisies create visual cohesion to this spatially integrated composition. In addition, words such as rain, washed, GREEN, under, outerwear and CLEAN evoke the auditory, visual and kinaesthetic senses in the poem. 


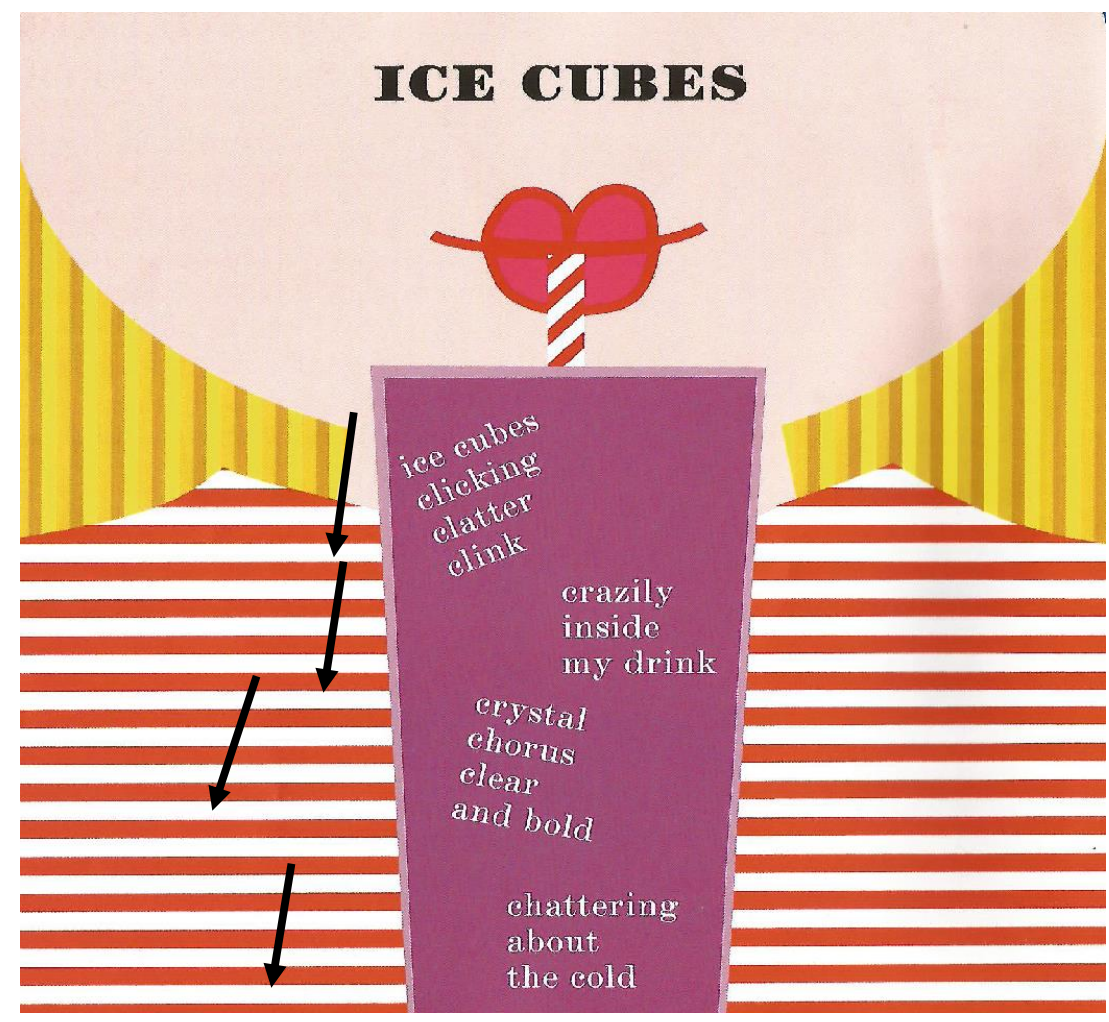

Figure 2: Ice Cubes

From SPLISH SPLASH. Text Copyright [c]1994 by Joan Bransfield Graham. Illustrations Copyright [c] 1994 by Steve Scott. Reprinted by permission of Houghton Mifflin Harcourt Publishing Company. All rights reserved.

In the second poem, Ice Cubes, the glass of ice cubes which is centred, colour blocked and foregrounded is perceived to have greater salience than the rest of the represented participants in the visual landscape. According to Moya (2014), a foregrounded element at the centre of a composition has greater salience than an element in the background.

Although the image of the girl's face is the largest element on the page, it is the glass which utilizes the block principle (Draper, 1971) that is visually arresting. The size of the centred glass carries weightage and makes it salient. This strengthens Moya and Pinar's (2008) assertion that the larger the represented, the greater the importance.

The salience of the glass is also achieved through overlapping where the glass is superimposed over the stripped t-shirt and the girl's neck. This supports Arnheim's (1974) claim that overlapping establishes a hierarchy by creating a distinction between dominating and subservient units. 
Salience is further emphasised by the red lips of the girl and the stripped straw. According to Machin (2007), saturated colours such as red, green and blue are regularly deployed in stories to evoke sensory experience. Similarly, sipping a cold drink stimulates the olfactory, gustatory, auditory and tactile senses.

The black bold uppercase fonts of the title 'ICE CUBES' also contribute to salience because of their size and weightage. Furthermore, the black fonts stand out against the rest of the colours on the page. This strengthens van Leeuwen's (2006) view that typographical salience can be achieved through size, colour contrasts and movement. In addition, the contrasting white fonts of the concrete poem are superimposed on the purple glass, thus making the poem distinguishable and prominent. According to Serafini and Clausen (2012), coloured fonts are deployed as contrasting tools to enable readers to read texts easily. On the other hand, Moya (2014) asserts that fonts and colours are often utilised in multimodal ensembles to indicate prominence. Therefore, both title and fonts are significant in Ice Cubes as they emphasize the subject of the poem.

The colour white that connotes cold frozen ice cubes adds realism to the poem by making the visuals a concrete representation of the object. Onomatopoeic words such as clicking, clatter, clink work together to contribute to the auditory, kinaesthetic and visual appeal in the poem. The 'ice cubes' also kinetically act out their meaning where they resemble falling ice cubes (as depicted by the arrows in Figure 2). These examples clearly support Kiefer's (1995) affirmation that colour is one of the most expressive elements and the intensity of a colour as well as the ways in which they are combined can affect the mood and evoke meaning. In sum, the dominance of colours in specific objects provides information and makes the objects noticeable and attractive (Nodelman \& Reimer, 2003).

Ice Cubes is an amalgamation of all six framing categories; segregation, integration, rhyme, contrast, repetition and overlap. In the visual layout, the concrete poem takes on the image of ice cubes which is placed onto the space occupied by the glass, thus lending itself to the framing category of integration. The words (concrete poem) are overlaid onto the image in a unified arrangement, thus, clearly becoming part of the image (Painter, Martin \& Unsworth, 2013).

The white and red stripped t-shirt that rhymes with the white and red stripped straw contributes to connectivity as the colours link the different pictorial images (t-shirt and straw). This connectivity is strengthened by the overlapping of the representational participants (the glass 
on the t-shirt, the face against the vertical lined background). Hence, the connection created by overlapping is considered close and dynamic.

The segregation and repetition of lines in the background and on the t-shirt are indicated by different colours. The series of vertical and horizontal lines are accorded differing thickness. This forms patterns and establishes uniformed connectedness. The combination of yellow (different shades) vertical lines of the background and the horizontal lines of the t-shirt also lends to connectivity as it creates stability (Jirousek, 1995) and unites the elements on the page. Arnheim (1974) postulates that the visual combination of lines produces a simpler figure as compared to a creation by separate lines. Thus, the combination of lines is seen as an integrated whole.

The coalescence of the different categories of framing adds to the rich layers of meanings in Ice Cubes. It can be deduced that the illustrator has successfully employed framing devices like lines and colours to join the various elements as one compositional unit. The visual analysis of Rain and Ice Cubes reveals that visual elements cohere and combine in meaningful ways to establish meanings on the page as discussed in the next section.

\section{Discussion of Visual Analysis}

The visual analysis of Rain and Ice Cubes highlights that the representation of visual elements in the poems reproduce the dominant theme of water and its forms. Words such as washed, outside and clean (Rain) and crystal, clear and cold (Ice Cubes) are synonymous to rain and ice-cubes respectively. In addition, the utilization of words not only represents the verbal and visual sphere of communication but also carries concrete aesthetic message. The employment of the colours blue (Rain) and white (Ice Cubes) also establishes connectivity with the theme of water. Furthermore, the integration of various images such as raindrops and daisies (Rain) and glass, straw and lips (Ice Cubes) in the layouts provides cohesion and further enhance the water themed poems.

The analysis also reveals that the interrelated systems of salience and framing work in tandem to construct meanings in the poems. The combination and interaction between the different features of salience such as size, placement, colour, foregrounding and overlapping draw attention to a specific visual element or elements and therefore, lend greater salience than the rest of the elements in the layouts.

For example, size plays a fundamental role in denoting salience in Rain and Ice Cubes and hence, the illustrator has afforded some elements greater space as compared to other elements. In 
doing so, prominent information status is given to the biggest element (Moya, 2014) as demonstrated in the discussion.

Colour, on the other hand, is important in creating attractive, engaging and eye-catching visuals for children. Salience attained through the feature of colour draws a reader's attention to the most significant element on the page and it is an invaluable source of information for visual communicators (Dondis, 1973). The utilization of bold vivid colours like red, orange, yellow and blue as in Rain and Ice Cubes is often associated with children's books. Therefore, attention is given to significant images in Rain and Ice Cubes through the features of salience.

The deployment of framing through the categories of integration, rhyming, repetition, overlapping, contrast and segregation in Rain and Ice Cubes clearly indicates that the images are unframed, thus emphasizing on group identity. For instance, the category of rhyming utilizes colour as a device to connect the different elements on the page and this provides the overall cohesion. This concurs with Rajendra (2016) who acknowledges that colour offers a sense of unity which contributes to cohesion.

Conversely, the framing category of repetition links all the visual elements as a single piece of information as illustrated in Rain and Ice Cubes. Gatto, Porter and Selleck (1987) opine that repetition of shapes and lines produces patterns that suggest unity. They further stress that these patterns provide visual enrichment and enjoyment for a reader.

However, the poems are devoid of framing through the category of separation (empty space and physical border) as the different elements are placed against a coloured background. The presence of connecting framing categories such as integration, rhyme and repetition produce a strong sense of unity between the elements in the layouts. Nevertheless, the illustrator has also brilliantly deployed disconnecting devices like contrasting colours and lines to present connectivity subtly. This distinctly reinforces Bateman's (2008) notion that a low degree of framing contributes to maximum link between the chosen element and its surrounding elements. Therefore, the absence of frame lines helps to connect words and images and this supports the intended meaning.

Moya (2014) puts forth that the exclusion of framing creates an inter-semiotic compositional cooperation between the visual and verbal elements. This is clearly indicated by the visual analysis of Rain and Ice Cubes where the different semiotic elements in the poems create a 
sense of visual and written unity. As a result, the combination of visual and verbal elements produces a meaningful whole and offers readers greater opportunities to create meanings.

Most importantly, the findings reveal that shapes, contours or invisible frame lines that constitute concrete poems do not adhere to Kress and van Leeuwen's (2006) VG which emphasizes that elements within frames are separated. Therefore, in children's concrete poems, shapes, contours or invisible frame lines do not isolate elements within a composition. They merge seamlessly with other visual elements to create unity and cohesion on the page.

Furthermore, the meaning in a stand-alone concrete poem is not prominent as compared to one that co-exist with other pictorial images (Figures 1 and 2). The verbal element (concrete poem) that is integrated with the visual elements creates a powerful union and establishes cohesion between the image and text (Kress \& van Leeuwen, 2006).

The amalgamation of words and images makes reading a pleasant experience as the bright and cheery palette delight children, capture attention and reinforce meaning. Moreover, this visual form of communication supports Salbego et al's (2015) notion that the analysis of representational, interactional and compositional meanings in terms of visual resources may scaffold students' learning processes by directing their attention to read images.

Most significantly, the study reveals how the illustrator adheres to the content and shape of the concrete poems to create an 'environment' for the poems. Therefore, both words and images work together in synergy to generate meanings. Hence, the visual representations support the content of the poems as the illustrator conforms to the ideas and shapes of the poems.

As Unsworth and Wheeler's (2002) insightfully put it, "If one were to read just the text and not the visuals... the available meanings would be greatly diminished" (p.68). Therefore, the poems are imbued with significant meanings through the utilization of images. This in turn may encourage students' understanding of the content they are studying (Salbego, Heberle \& Balen, 2015).

This study reveals that multimodal analysis is another way to interpret and construct meanings especially in children's poems through analysing how visual images are represented in a composition. Furthermore, the findings also concur with Eleftheriou et al (2013) who opine that the pictorial text may be linked to another type of text (e.g.written) to shape a multimodal message.

Therefore, multimodal analysis could be introduced in the classroom so that students would have an in-depth knowledge on how multimodal resources are employed in meaning-making. In 
addition, it provides teachers the opportunity to use other types of multimodal ensembles to develop visual literacy in the classroom.

\section{Conclusion}

This study explored the visual elements in children's concrete poems through multimodal analysis using Kress and van Leeuwen's VG which proves to be a powerful tool in the study of multimodal texts (Moya, 2010).

The analysis reveals that textual and visual elements with their distinguishable properties coexist to contribute meanings in Rain and Ice Cubes. This collaboration is pertinent to the interpretation of the poems. In view of this, the various multimodal elements offer intelligible input and provide greater depth of comprehension, recognition and recollection and hence, facilitates the understanding of the poems. In addition, the images furnish readers with clues in interpreting the words in the poem.

As a result, the visual representation (concrete poems and pictorial images) produces an attractive and meaningful whole as the organization of the different elements works in harmony on the page to create something which is visually compelling. Similarly, it also adheres to the Gestalt Theory of 'the whole is better than the sum of its parts'.

Due to the scarcity of multimodal analysis in children's concrete poems, this study may act as a foundation for further research in this area. It could also address the question of how different modes in multimodal ensembles are represented and how they weave together to realize meanings. In addition, the study could contribute to the possibilities of analysing and interpreting other forms of illustrated poems such as nursery rhymes, limericks, haikus, ballads and so forth, in relation to generalising the findings. This encourages a comparative analysis between the different forms of poems and illuminates the exploration of different features and dimensions in the poems.

In addition, more studies on multimodal analysis are necessary for the clarification and refinement of Kress and van Leeuwen's VG. In doing so, it is a significant step in strengthening the idea of establishing meaning through word-image interaction in the minds of researchers, practitioners and policy-makers. In short, multimodal analysis of concrete poems could be considered as a mean to explore multimodal meaning-making in children's literature. 


\section{Acknowledgments}

The data (images) in this paper is reprinted with permission from the Director of Permissions, HMH Trade Publishing, New York, NY 10016, USA

\section{References}

Arnheim,R. (1974). Art and visual perception: A Psychology of the creative eye, (rev.edn.). Berkeley: University of California Press.

Baldry, A. \& Thibault, P. J. (2006, 2005). Multimodal transcription and text analysis: A multimodal toolkit and coursebook. London: Equinox.

Bateman, J. A. (2008). Multimodality and genre: A foundation for the systematic analysis of multimodal documents. New York: Palgrave Macmillan.

Bodden, V. (2010). Poetry basics: Concrete poetry. Minnesota: Creative Education.

Bohn, W. (2011). Reading visual poetry. Maryland: Fairleigh Dickinson University Press.

Borkent, M. (2010). The materiality of cognition: Concrete poetry and the embodied mind. Wreck $3(1)$.

Carter, D. (1998). Teaching poetry in the primary school: Perspectives for a new generation. London: David Fulton Publishers Ltd.

Cheong, H.F., \& Kaur, S. (2015). Legitimising male grooming through packaging discourse: a linguistic analysis. Social Semiotics. 25 (3), 364-385. Retrieved from http://www.tandfonline.com/loi/csos20. DOI: 10.1080/10350330.2015.1026650.

Ci-Shu, Shen. \& Yi-Ping,Wu. (2012). Translating beyond languages: The challenges of rendering Taiwan's visual concrete poems in English. The AALITRA Review: A Journal of Literary Translation. No 5. Melbourne: Monash University. 15-30. Retrieved from www.nla.gov.au/openpublish/index..../2964

Dondis, D.A. (1973). A primer of visual literacy. Cambridge, MA: MIT Press.

Draper, R.P. (1971). Concrete Poetry. New Literary History. 2(2), 329-340.

Eleftheriou, P., Stamou, A.G., Alevriadou, A. \& Tsakiridou. (2013). A comparative study of representations about disability in primary school children's drawings: a sociosemiotic approach. Social Semiotics, 23(5), 663-674. Retrieved from http://www.tandfonline.com/loi/csos20. DOI: 10.1080/10350330.2012.739002. 
Gatto, J.A., Porter, A.W., Selleck, J. (1987). Exploring visual design (2 ${ }^{\text {nd }}$ edn.). Massachusetts: Davis Publications, Inc.

Graham,J.B. (1994). Splish splash. New York, NY: Houghton Mifflin Company.

Halliday, M.A.K. (1994). Functional grammar. London: Edward Arnold.

Jewitt,C.(2009). An introduction to multimodality. In C. Jewitt (Ed.), The Routledge handbook of multimodal analysis. New York, NY: Routledge.

Jirousek, C. (1995). Introduction to the elements of design: Point. Retrieved from char.txa.cornell.edu/language/element.htm

John, A.E., \& Olajoke, A.S. (2012). Engaging with Old Testament stories. A multimodal social semiotic approach to children bible illustrations. International Journal of Applied Linguistics \& English Literature, 1(5), 219-225. Retrieved from

https://www.academia.edu/40649226/Engaging_with_Old_Testament_Stories_A_Multimo dal_Social_Semiotic_Approach_to_Children_Bible_Illustrations

Joshi, A. R. (2009). Untranslatability in the visual arts: Examples from visual concrete poetry. Translation Today, 6(1\&2), 1-29. Retrieved from www.ntm.org.in/.../Articles/01\%20$\% 20$ Untranslatability\%20in\%20the\%

Jumaah, A.N.F. (2019). Visual representations of Iraqi refugees in DEUTSCHE WELLE. (Unpublished Masters dissertation). University of Malaya.

Kabuto, B. (2009). Color as a semiotic resource in early sign making. Early Childhood Research \& Practice, 11(2), 1-20.

Khoo, M.Y.L. (2019). Multimodality in the front covers of chick lit book. (Unpublished Masters dissertation). University of Malaya.

Kiefer, B. (1995). The potential of picturebooks: From visual literacy to aesthetic understanding. Englewood Cliffs, New Jersey: Prentice-Hall, Inc.

Knowles,K., Schaffner,A.N., Weger,U., \& Roberts, A.M. (2012). Reading space in visual poetry: New cognitive perspectives. Writing Technologies, Volume 4, 75-106.

Kress, G. (2008). "Literacy” in a multimodal environment of communication. In J. Flood, S.B. Heath \& D. Lapp (Eds.), Handbook on teaching literacy through the communicative and visual arts, Volume 2, 91-100. New York: Lawrence Erlbaum Associates.

Kress, G. (2010). Multimodality: A social semiotic approach to contemporary communication. London: Routledge. 
Kress,G. \& van Leeuwen,T. (2006/1996). Reading images: The grammar of visual design. London: Routledge.

Kress,G. \& van Leeuwen,T. (2002). Colour as a semiotic mode: Notes for a grammar of colour. Visual Communication, 1(3), 343-368.

Ledin,P., \& Machin, D. (2018). Doing visual analysis: From theory to practice. London: SAGE Publications Ltd.

Machin,D. (2007). Introduction to multimodal analysis. London: Hodder Arnold.

Machin, D., \& Mayr, A. (2012). How to do critical discourse analysis. London: SAGE Publications Ltd.

Md Sidin Ahmad Ishak. (2007). Graphic Communication: Concepts and practice. Kuala Lumpur: University Malaya Press.

Meyer, M. (2017). Concrete research poetry: A visual representation of metaphor. Art/Research International: A Transdisciplinary Journal, 2(1), 32-57.

Ministry of Education. (2001). English curriculum for primary schools in Malaysia. Curriculum Development Centre.

Moya,A.J. (2010). A multimodal analysis of The Tale of Peter Rabbit within the interpersonal metafunction. ATLANTIS: Journal of Spanish Association of Anglo-American Studies, 32 (1), 123-140. Retrieved from http://www.atlantisjournal.org/ARCHIVE/32.1/2010MoyaGuijarro.pdf

Moya, A. J. (2014). A multimodal analysis of picture books for children: A systemic functional approach. Sheffield, United Kingdom: Equinox Publishing Ltd.

Moya, A. J. \& Pinar, M.J. (2008). Compositional, interpersonal and representational meanings in a children's narrative: A multimodal discourse analysis. Journal of Pragmatics, 40 (9), 16011619.

New London Group. (1996). A pedagogy of multiliteracies: Designing social futures. Harvard Educational Review. Volume 66. 60-92.

Nikolajeva, M. \& Scott, C. (2000, 2006). The dynamics of picturebook communication. Children's Literature in Education. 31 (4), 225-239.

Nodelman,P. \& Reimer, M. (2003). The pleasures of children's literature (3 ${ }^{\text {rd }}$ ed.). Boston: Allyn \& Bacon. 
Painter,C., Martin, J.R. \& Unsworth, L. (2013). Reading visual narratives: Image analysis of children's picture books. London: Equinox Publishing.

Rajendra, T. R. (2016). A multimodal analysis of graphic novels used in the Malaysian English language classroom. (Unpublished Ph.D thesis). University of Malaya, Kuala Lumpur.

Robertson, J. (2008). Fourth and fifth grade classroom case study of response to multimodal representations in children's picture books. (Doctoral Thesis). Syracuse University. Retrieved from ProQuest Database.

Russel, D. L. (2009). Literature for children: A short introduction $\left(6^{\text {th }}\right.$ ed). Boston: Allyn and Bacon.

Salbego,N., Heberle,V.M. \& Balen,M.G.S. da Silva. (2015). A visual analysis of English textbooks: Multimodal scaffolded learning. Calidoscopio, 13 (1), 5-13.

Serafini, F. (2014). Reading the visual: An introduction to teaching multimodal literacy. New York: Teachers College Press.

Serafini, F. (2012). Reading multimodal texts in the $21^{\text {st }}$ century. Research in the Schools, 19(1), 26-32.

Serafini, F. (2011). Expanding perspectives for comprehending visual images in multimodal texts. Journal of Adolescent \& Adult Literacy, 54 (5), 342-350.

Serafini, F. \& Clausen, J. (2012). Typography as semiotic resource. Journal of Visual Literacy, 31(2), 12-29.

Shen, C., \& Wu, Y. (2012). Translating beyond languages: The challenges of rendering Taiwan's visual concrete poems in English. The AALITRA Review: A Journal of Literary Translation, 5, 15-30. Retrieved from www.nla.gov.au/openpublish/index..../2964

Tan, P.W. (2017). A systemic functional linguistic study of experiential meanings in tourism brochures. (Unpublished Doctoral dissertation). University of Malaya.

Unsworth, L. (2001). Teaching multiliteracies across the curriculum: Changing contexts of text and image in classroom practice. Buckingham, United Kingdom: Open University Press.

Unsworth, L. \& Wheeler, J. (2002). Re-valuing the role of images in reviewing picture books. Reading Language and Literacy. 36 (2), 68-74.

van Leeuwen, T. (2005). Introducing social semiotics. Oxon: Routledge.

van Leeuwen, T. (2006). Towards a semiotics of typography. Information Design Journal, 14(2), 139-155. 
van Leeuwen, T. (2011). The language of colour: An introduction. Oxon: Routledge.

Wang, X. (2012). A study of visual poem "in Just" - from the perspective of multimodal discourse analysis. Theory and Practice in Language Studies, 2(12), 2649-2654. 